\title{
A indústria fonográfica e os novos modelos de negócios analisados através da Nova Economia Institucional
}

\author{
Míriam C. Toyama* \\ Rachel P. Benze \\ Mauro R. Côrtez ${ }^{* * *}$
}

RESUMO - Este artigo analisa da perspectiva da Nova Economia Institucional a recente queda de desempenho da indústria fonográfica, a qual alguns pesquisadores afirmam ter sido causada por inovações como os arquivos MP3 e o surgimento de novos modelos de negócios.

Palavras-chave: Indústria fonográfica. Pirataria. Novos modelos de negócios.

\section{INTRODUÇÃO}

A partir da década de 70 até o final da década de 90 a indústria fonográfica apresenta vendas e lucros crescentes. Entretanto, a partir do final de 1999 o desempenho da indústria fonográfica começou a se deteriorar, a indústria começou a apresentar crescentes quedas de lucros e vendas. Foram apontados como causa da queda no desempenho da indústria fonográfica o surgimento de uma série de inovações tecnológicas as quais permitem que o consumidor final realize downloads ilegais de músicas protegidas pelos direitos autorais, dessa forma obtendo as músicas de graça.

O objetivo deste artigo é discutir essa queda no desempenho da indústria da perspectiva da Nova Economia Institucional (NEI), e analisar o posterior surgimento de uma série de novos modelos de negócios, novos contratos, que tentam se estabelecer e se legitimar nesta indústria.

\section{A INDÚSTRIA E SEUS PRODUTOS}

De acordo com Liebowitz (2002), músicas são bens de informação e estes são caracterizados por terem um custo fixo muito alto e um custo de reprodução muito baixo,

\footnotetext{
* Mestre em Economia pela UEM. Professora substituta do departamento de Ciências Sociais da Universidade Federal de São Carlos (UFSCar). Endereço eletrônico: miriamtoyama@gmail.com.

** Mestre em Engenharia de Produção.

*** Doutor em Ciências da Engenharia ambiental. Professor do Departamento de engenharia de Produção da Universidade Federal de São Carlos (UFSCar).
} 
assim, como afirmam Shapiro e Varian (1999), o mais caro para as gravadoras é produzir a primeira cópia de cada produto, as cópias seguintes são significativamente mais baratas.

Outro ponto importante é que os bens de informação, de acordo com Liebowitzs (2003), Landes e Posner (1989) e Shapiro e Varian (1999), possuem características de bens públicos. Assim, as músicas possuem a característica de não exclusão, dessa forma, quando elas são lançadas é impossível impedir as pessoas que não pagaram por ela se beneficiarem de sua existência. As músicas, assim como todos os outros bens de conhecimento, também possuem consumo não-rival, dessa forma o consumo de um indivíduo não afeta o dos outros. Sem nenhuma forma de proteção as músicas seriam alvo fácil para o comportamento free rider.

Por causa destas características de bens públicos, as músicas, que são os produtos da indústria fonográfica, são protegidas pelos direitos autorais. Isso porque, como afirmam Shapiro e Varian (1999), já que além das características de bens públicos, o custo de reprodução deste bem é baixo, se não houvessem barreiras à entrada nesta indústria as empresas que realizam o primeiro investimento, de produzir as músicas pela primeira vez, estariam em uma situação desfavorável. A legislação de direitos autorais funciona como uma barreira à entrada, garantindo um monopólio temporário nas mãos dos autores das músicas (TOWSE, 2000).

Assim, a legislação de direitos autorais, de acordo com Akerlof et al. (2002), ao estabelecer o preço das músicas acima do custo marginal, está beneficiando a sociedade como um todo ao incentivar a produção destes bens.

Outra característica das músicas é que elas também são consideradas como bens experimentais. Assim, de acordo com Andersen et al. (2000), Shapiro e Varian (1999) e Molteni e Ordanini (2003), o consumidor só consegue saber o valor da música quando a experimenta.

Para que a música seja produzida e se torne um produto, um CD, DVD ou mesmo um arquivo digital, é preciso a interação de vários agentes. Frederiksen (2002) divide estes agentes em três categorias: main activities (produção, administração de direitos autorais, promoção e distribuição etc.), related activities (fotografia, impressa etc.) e related industries (internet, empresas de software etc.).

Uma vez gravada, a música poderia ser vendida várias vezes ao mesmo consumidor, através de álbuns, trilhas sonoras e coletâneas. Para chegar ao consumidor, de acordo com um estudo da OECD (2004), a música era anunciada e promovida pelo rádio, TV e internet, depois ela cumpria um longo caminho até o consumidor, passando pelos canais de distribuição, lojas 
varejistas, lojas especializadas, não especializadas e comércio eletrônico.

Com relação a estrutura da indústria, temos uma estrutura altamente concentrada, o que de acordo com Lessig (2004), leva a grande homogenização entre os produtos e empresas. O mercado mundial de música é dominado pela América do Norte e Europa, enquanto que o mercado asiático é dominado pelo Japão.

A concentração da indústria não se restringe aos mercados mais significativos, mas se estende as gravadoras. Em 2004 (IFPI, 2005), o mercado mundial estava dividido entre quatro grandes gravadoras: Universal com 25,5\%, Sony BMG com 21,5\%, EMI com 13,4 e Warner com 11,3\%. E destas grandes empresas apenas a EMI se concentra apenas na indústria de música, sendo que para as outras empresas a renda proveniente desta indústria representa de $10 \%$ a $33 \%$ do total.

De acordo com Silva e Ramello (2000), o restante deste mercado é preenchido por pequenas gravadoras independentes. O papel das gravadoras independentes é o de inovar, investir em novos artistas e novas tendências, geralmente, quando estes novos artistas começam a fazer sucesso eles passam para as grandes gravadoras.

\section{INOVAÇÕES TECNOLÓGICAS E INDÚSTRIA FONOGRÁFICA}

No final da década de 90 o desempenho da indústria de música começa a cair. Como responsável por esse mau desempenho as associações da indústria fonográfica e alguns pesquisadores apontaram o surgimento de uma série de inovações tecnológicas, principalmente os arquivos MP3.

Os arquivos MP3 surgiram como resultado de pesquisas sobre codificação de arquivos de áudio e vídeo do Instituto Integrierte Schaultungen e da Universidade de Erlangena. Esse tipo de arquivo permite que os arquivos de áudio mantenham certa qualidade mesmo sendo compactados, sendo que no processo de compactação são eliminadas as frequências não captadas pelo ouvido humano.

Como estes arquivos são extremamente leves, se tornam facilmente transmitidos pela internet e a princípio eles eram disponibilizados em sites e blogs. Então, o surgimento de programas de compartilhamento de arquivos facilitaram a troca de arquivos de música pela internet, pois permitem que os usuários destes softwares procurem as músicas nos computadores dos outros usuários.

A RIAA (Recording Industry Association of America) inicia uma onda de processos contra os responsáveis pelas redes de trocas de arquivos. Como as redes evoluíram e não 
permitiram mais processos aos responsáveis, a RIAA iniciou processos contra os usuários das redes. O volume de downloads ilegais caiu, mas logo voltou a subir, pois também surgiram novos tipos de redes, que permitem ao usuário esconder seu número IP, impedindo sua identificação.

De acordo com Lessig (2004) nem todos os usos das redes de compartilhamento de arquivos são prejudiciais às gravadoras: os usuários poderiam usar as redes para obter material que já se encontra em domínio público, ou material que ainda é protegido, mas que não se encontra mais disponível ou para testar as músicas antes de adquirí-las legalmente (sampling). Segundo o autor haveria apenas um uso prejudicial: substituir a compra de música pelo download ilegal.

Uma série de outras inovações facilitaram ou a realização do download ilegal ou a utilização dessa música pelo consumidor. Uma dessas inovações foi a internet de banda larga, de acordo com um estudo realizado na Europa, 50\% dos usuários de internet mudaram para a banda larga com a finalidade de realizar downloads ilegais (OECD, 2004).

Entretanto, de acordo com um estudo da OECD (2004), o surgimento da banda larga não serve apenas para prejudicar a indústria fonográfica, viabilizando downloads ilegais de forma mais rápida. Mas também oferece um novo canal de distribuição de música, e permite o surgimento das lojas virtuais de música, como o iTunes.

Outras inovações que afetam a indústria fonográfica são os gravadores de CD e DVD e os tocadores de MP3. Ambos oferecem mais comodidade ao consumidor, pois permitem que as músicas obtidas através dos downloads, tanto legais quanto ilegais, sejam apreciadas longe do computador. De acordo com a Parks and Associates, 20\% dos consumidores de música digital nos Estados Unidos possuíam gravadores de CD em 2003 (PEITZ e WAELBROECK, 2004b).

As associações da indústria fonográfica afirmam que estas inovações, principalmente os arquivos MP3 e as redes de troca de arquivos, são prejudiciais aos seus negócios e também são a principal causa da queda em suas vendas e lucros. Liebowitzs (2004a) afirma que até mesmo o efeito sampling é prejudicial, uma vez que os álbuns são compostos de música e informação, a partir do momento que os consumidores obtém a informação através dos downloads ilegais eles precisam de uma demanda menor para se satisfazer. Outros autores como, Peitz e Welbroeck (2004a), afirmam que os downloads ilegais são responsáveis por parte do mau desempenho da indústria fonográfica, mas não por todo. Entretanto, os autores não entram em um consenso a respeito de quão prejudiciais são os 
downloads ilegais.

\section{NOVA ECONOMIA INSTITUCIONAL E OS DESAFIOS DA INDÚSTRIA FONOGRÁFICA}

A atual situação da indústria fonográfica pode ser analisada da perspectiva da Nova Economia Institucional (NEI). De acordo com esta teoria além dos custos de produção, devem também ser considerados os custos de transação. De acordo com Fiani (2002), os custos de transação são relacionados a negociação e elaboração dos contratos, assim como as medidas necessárias para que o contrato seja cumprido. Também parte do pressuposto de que os indivíduos possuem níveis de racionalidade e de oportunismo, e devido a essa racionalidade limitada os contratos estabelecidos entre os agentes são incompletos, abrindo brechas para ações oportunistas.

No caso da indústria fonográfica e o presente modelo de negócios, baseado nas grandes empresas e na proteção através dos direitos autorais, os custos de transação ficam claros quando consideramos o caso da Universal, que em 2005 tentava lançar uma coletânea dos trabalhos de Ronnie Von, mas não conseguiu, pois não encontorou todos os donos dos direitos autorais das músicas.

De acordo com Fiani (2002), as normas que regulam o comportamento dos agentes podem ser formais ou informais. As regras formais precisam ser legitimadas, de forma que sejam aceitas pelos agentes. Os direitos autorais relacionados as músicas que circulam pela internet não são considerados legítimos por grande parte dos usuários, os quais não enxergam a pirataria virtual como sendo algo errado.

Outro problema é a baixa capacidade de enforcement - a capacidade das instituições envolvidas em garantir que o contrato será cumprindo - neste modelo de negócios. Se a capacidade de enforcement fosse tal que garantisse o cumprimento dos contratos, impedindo a troca de arquivos de música pela internet, isso legitimaria a norma dos direitos autorais, entretanto, não é o que acontece.

Como observa Benze et al. (2009) a capacidade de enforcement é dificultada pela arquitetura das redes. Atualmente as redes não possuem mais um servidor central, a qual controla o que é trocado entre os usuários, os próprios computadores dos usuários funcionam como mini centrais, ou as conexões são feitas diretamente entre os computadores . Outro fator é que a cada solução tecnológica que a indústria coloca para proteger seus bens (DRM, processos contra os usuários) surgem inovaçõs que impedem essas soluções, como quebra de 
códigos e softwares que escondem o número IP.

Dessa forma, todos estes fatores dificultam e diminuem a capacidade de enforcement, e quanto maiores os gastos com enforcement, maior o preço dos produtos. Isso, por sua vez atua como incentivo aos downloads ilegais. Pois como afirma Benze et al. (2009), as grandes gravadoras já são vistas como vilãs da situação, já que os preços dos produtos são altos. Para alguns dos usuários das redes de troca e alguns pesquisadores (TOWSE, 2000; PEITZ e WAELBROECK, 2004a) a porcentagem do preço que se destina aos artistas é muito pequena.

Diante desta situação, começaram a surgir novos modelos de negócios, que podem ser vistos como novos tipos de contratos, na perspectiva da NEI. Segundo a OECD (2004), as inovações citadas anteriormente propiciaram o surgimento da venda de música no formato digital. Neste novo modelo de negócios, gravadoras e artistas continuam desempenhando o mesmo papel de antes, os artistas produzem as músicas e as gravadoras fazem a seleção do que deve ser gravado e vendido. Neste modelo obsrevamos a integração de canais de distribuição de conteúdo através da internet, e a entrada de uma série de empresas, como empresas de software responsáveis pela compressão das faixas, desenvolvimento de DRM. Dessa forma, como afirma Benze et al. (2009), as empresas fonográficas podem economizar com distribuição e logistica, obter um produto customizado e com possibilidade de preços inferiores aos dos CDs. Assim, as músicas podem ser vendidas por faixas individuais ou através de uma assinatura que permite ao consumidor realizar quantos downloads quiser dentro de um período de tempo (BENZE et al. 2009 e PEITZ e WAELBROECK, 2004b). Outra oportunidade é a venda de música para celulares.

Também foi criada uma nova forma de proteger as músicas e os outros bens culturais, o Creative Commons. As licenças Creative Commons funcionam como contratos, os quais variam e podem oferecer o mesmo nível de proteção que os direitos autorais, ou podem permiter a terceiros utilizar os trabalhos do agente da forma como quiserem.

Entretanto, as novas formas de contratos listadas anteriormente continuam tendo baixa capacidade de enforcement, pois a gratuidade dos downloads ilegais acaba minando a eficiência destes novos modelos (BENZE et al. 2009).

Alguns artistas e gravadoras, como observa Benze et al. (2009), adotaram modelos de negócios mais radicais, os quais consistem em disponibilizar integralmente e gratuitamente os trabalhos dos artistas. Geralmente o objetivo é divulgar o artista e atrair público para os shows. Ainda de acordo com os autores, existe a possibilidade de downloads remunerados, nos quais os 
downloads gratuitos para os consumidores são pagos pelas empresas patrocinadoras.

\section{CONCLUSÃO}

Como pudemos observar, as inovações tecnológicas, as quais permitem aos consumidores em potencial da indústria fonográfica realizarem downloads ilegais, também abrem uma série de oportunidades para novos modelos de negócios. De acordo com Wilde e Schwerzmann (2004), a demora em incorporar as inovações e adotar novos modelos de negócios foi, em parte, responsável pelo mau desempenho da indústria após o final da década de 90 .

Alguns pesquisadores, como Ramello (2004c) e Towse (2000) afirmam que os processos contra os usuários e as tentativas de fortalecimento dos direitos autorais são uma tentativa de proteger um modelo de negócios. Por outro lado, como observam Benze et al. (2009), as pequenas gravadoras têm experimentado um período de crescimento.

Dessa forma o surgimento de novos modelos de negócios vêm de encontro com as necessidades da indústria fonográfica, de encontrar novas formas de vender e lucrar com seus produtos. Isso porque como afirma a ABPD (2010), as vendas de música em formato tem crescido, mas ainda não cobre as perdas em vendas de mídia física. $\mathrm{O}$ que se torna importante é descobrir se estes novos modelos de negócios serão capazes de serem institucionalizados, e se tornarem legítimos aos olhos dos consumidores.

\section{REFERÊNCIAS}

AKERLOF, G. et al. On writ of certiorari to the United States Court of appeals for the Districti of Columbia circuit. 2004.

ANDERSEN, B., et al. Copyrights, competition and development the case of the music industry, UNCTAD, 2000.

BENZE, R. et al. A crise da indústria fonográfica analisada sob a perspectiva da Nova Economia Institucional. ENEGEP: Salvador: 2009.

FIANI, R. Teoria dos custos de transação. In: KUPFER, D. e HASENCLEVER, L. Economia Industrial. Rio de Janeiro: Campus, 2002.

IFPI. Disponível em: <www.ifpi.com>.

FREDERIKSEN, L. Innovation? The fuzzy case of pop music industry. DRUID summer conference on Industrial dynamics of the new and old economy- who is embracing whom?. Copenhagen: Elsinore, jun./2002.

LANDES, W. M. e POSNER, R. A. An economic Analysis of copyright law. Journal of legal studies, n. 18, 1989. 
LESSIG, L. Free culture. How big media uses technology and law to lock down culture and control creativity. 2004. Disponível em <www.lessig.org>. Acesso em: 4/8/2005.

MOLTENI, L. and ORDANINI, A. Consuption patterns, digital tecnology and music download. Long Range Planning, n. 36, 2003.

LIEBOWITZ, S.J. Policing pirates in the networked age. Policy analysis, n. 438. mai./2002.

LIEBOWITZ, S. J. Will Mp3 download annihilate the record industry? The evidence so far. School of Management. University of Texas: Dallas, jul./2003.

OECD. Digital broadbad content: music. Directorate for science, technology and industry, Junho 2005. Disponível em: <www.oecd.org/dataoecd/13/2/34995041.pdf>. Acesso em: 20/10/2005.

RAMELLO, G.B. Private appropriability and sharing of kwnoledge: convergence or contradiction_ The oppostie tragedy of the creative commons. ELGAR. E. Developments the economics of copyright, mai./2004 b.

RAMELLO, G.B. Intelectual property and the markets of ideas. Liuc Papers, n. 161, dez./ 2004c.

SILVA, F. e RAMELLO, G.B. Sound recording market: the ambiguous case of copyright and piracy. Industrial and Corporate Change, Oxford ,v. 9, n 3, p. 415-442, 2000.

SHAPIRO, C. e VARIAN, H. R. A economia da informação. Como os princípioseconômicos se aplicam à era da informática. Rio de Janeiro: Campus. 2 e.,1999.

TOWSE, R. Copyright and the cultural industries: incentives and earnings. Paper for presentation to the Korea informedia lawyers association, Seul, out./2000.

WAELBROECK, P.; PEITZ, M. An economist's guide to digital music. CESifo Working paper, n. 1333, 2004.

WILDE, E. SCHWERZMANN, J. When business models go bad: the music industry's future. ICETE 2004. Disponível em: < http://dret.net/netdret/docs/wilde-music-icete2004.pdf>. Acesso em: 14/1/2006. 